\title{
Potential Applications of Chitosan Nanoparticles as Novel Support in Enzyme Immobilization
}

\author{
${ }^{1}$ Hoda Jafarizadeh Malmiri, ${ }^{1}$ Mohammad Ali Ghaz Jahanian and ${ }^{2}$ Aydin Berenjian \\ ${ }^{1}$ Department of Chemical Engineering, Sahand University of Technology, Tabriz, Iran \\ ${ }^{2}$ School of Chemical and Biomolecular Engineering, The University of Sydney, Sydney, Australia
}

Received 2012-09-03, Revised 2012-09-24; Accepted 2012-09-27

\begin{abstract}
Chitosan is an attractive natural biopolymer from renewable resources with the presence of reactive amino and hydroxyl functional groups in its structure. Due to the good biocompatibility of chitosan, it can be used in magnetic-field assisted drug delivery, enzyme or cell immobilization and many other industrial applications. In the past decade, nanotechnology has been a considerable research interest in the area of preparation of immobilized enzyme carriers. This study looks at characteristics and applications of chitosan and chitosan nanoparticles and their potentials as suitable supports for enzyme immobilization. Results indicated that activity of immobilized enzymes and performance of enzyme immobilization onto chitosan nanoparticles are higher than chitosan macro and microparticles. As compared to other biopolymers nanoparticles, application of chitosan nanoparticles to immobilize enzymes strongly increases stability of immobilized enzymes and their easy separability from the reaction mixture at the end of the biochemical process.
\end{abstract}

Keywords: Chitosan, Chitosan Nanoparticles, Immobilized Enzyme, Support, Enzyme Activity, Stability

\section{INTRODUCTION}

Enzymes are proteins that catalyze chemical reactions. Unlike more traditional organic and inorganic catalysts, enzymes are large and fragile molecules. Instability and sensitivity to process conditions are disadvantages of using soluble enzymes. Therefore, application of solid phase biocatalysts has become more and more important during the last decades (Biro et al., 2008). Immobilized enzymes have a great importance in industrial bioprocesses especially in food, nutritional and pharmaceutical technologies (Sheldon, 2007). There are several reasons for using an enzyme in an immobilized form. In addition to more convenient handling of the enzyme, it provides for its facile separation from the product. It helps to prevent the contamination of the substrate with enzyme/protein or other compounds, which decreases purification costs (Spahn and Minteer, 2008). Immobilization also facilitates the efficient recovery and reuse of costly enzymes, with longer half lives and less degradation, in successive batches, or the process can eventually be carried out in a continuously operating reactor (Shi et al., 2011b).

There are several methods used to immobilize enzymes and three of the most common methods are physical adsorption, entrapment (encapsulation) and cross linking or covalently binding to a support (Janssen et al., 2002; Sheldon, 2007). For practical purposes, carrier beads with size falling into millimeter range are mainly used. However, more and more results are reported on immobilization of enzymes onto microparticles possessing high specific surface area and numerous active sites available for the enzyme molecules to be fixed. Moreover, because of the smaller size of the support particles, the internal diffusion hindrance diminishes (Biro et al., 2009). Hindrance can be described as a function of solute size and geometric properties of the porous network. Diffusion of macromolecules in porous structures is hindered in comparison to diffusion in free solution (Schroder et al., 2006). Various supports have been used for enzymes immobilization such as synthetic organic polymers, biopolymers, hydrogels, smart polymers and inorganic

\footnotetext{
Corresponding Author: Hoda Jafarizadeh Malmiri, Department of Chemical Engineering, Sahand University of Technology, Tabriz, Iran
} 
supports (Katchalski-Katzir and Kraemer, 2000; Lozinsky et al., 2003; Sheldon, 2007; Salemi, 2010). A variety of biopolymers, mainly water insoluble polysaccharides such as cellulose, starch, agarose and chitosan and proteins such as gelatin and albumin have been widely used as supports for immobilizing enzymes (Krajewska, 2004; Spahn and Minteer, 2008).

Chitosan with some primary amino groups is derived by deacetylation of chitin. Its $\mathrm{pK}_{\mathrm{a}}$ is about 6.3 (Sorlier et al., 2001). At lower $\mathrm{pH}$ solutions $\left(<\mathrm{pK}_{\mathrm{a}}\right)$, most of the amino groups are protonated, making chitosan a water soluble polyelectrolyte. When the $\mathrm{pH}$ is higher than $\mathrm{pK}_{\mathrm{a}}$, the amino groups are deprotonated and chitosan becomes insoluble. Because of its excellent film forming ability, biocompatibility, nontoxicity, high mechanical strength, cheapness and a susceptibility to chemical modifications, chitosan has been extensively used for immobilization of enzymes (Vaillant et al., 2000; Kilinc et al., 2002; Wei et al., 2002; Krajewska, 2004; Liang et al., 2005; Luo et al., 2005; Tang et al., 2006; Yang et al., 2010).

In recent years, nanotechnology has showed a significant attraction to the preparation of immobilized enzymes. Nanomaterials due to their small size and large surface area to volume ratio have special characteristics, which make them favourable for enzyme immobilization (Tang et al., 2006; Li et al., 2008). Therefore the objectives of the present study are: (i) to evaluate characteristics of suitable immobilized enzyme supports such as chitosan, (ii) to study properties, production methods and applications of chitosan nanoparticles and (iii) to evaluate advantages of using chitosan nanoparticles as suitable support for enzyme immobilization.

\subsection{Immobilized Enzyme Supports}

Immobilization is often the key to optimizing the operational performance of an enzyme in industrial processes, particularly for use in non aqueous media. The immobilization of enzymes has been a growing field of research, because it has allowed enzymes to be easily reused multiple times for the same reaction with longer half lives and less degradation and has provided a straightforward method of controlling reaction rate as well as reaction start and stop time (Mateo et al., 2007; Spahn and Minteer, 2008; Shi et al., 2011b).

The properties of immobilized enzymes are governed by the properties of both the enzymes and the support materials (Sheldon, 2007). The interaction between the two lends an immobilized enzyme specific physico-chemical and kinetic properties that may be decisive for its practical application and thus, a support judiciously chosen can significantly enhance the operational performance of the immobilized system (Krajewska, 2004).
Suitable materials used as a carrier should have chemical, physical and biological stability during processing, as well as in the reaction conditions; sufficient mechanical strength, specially for its utilization in reactors and industries; should be nontoxic both for the immobilized enzyme/bioparticle, as well for the product; also should have adequate function groups for binding biocatalyst and high loading capacity (Gorecka and Jastrzebska, 2011). Other criteria, such as structural characteristics (porosity, swelling, compression, material and mean particle behavior), as well as possibility for microbial growth, biodegradability, high affinity to proteins, solubility, regenerability and ease of preparation in different geometrical configurations that provide the system with permeability and surface area are more application specific (Krajewska, 2004). Chemical structure of carrier material determines interaction with enzymes. If the support material is highly porous, pore size and pore size distribution will play an important role in determining the immobilized enzyme properties. A small pore size can cause diffusion limitation resulting in structural rearrangement of the enzymes and subsequent inactivity. However, for very large pore sizes, enzymes can cluster together and thus lose activity (Miletic et al., 2012).

Enzymes immobilization onto carriers has been extensively studied and applied in many fields, such as biocatalysts (Hou et al., 2007; Li et al., 2010) medical devices (Liang et al., 2000; Lao et al., 2008), drug delivery systems (Gan and Wang, 2007; Shi et al., 2011a) and biosensor (Ley et al., 2011; Samanta and Sarkar, 2011). Several carriers such as synthetic organic polymers (e.g., Eupergit $\mathrm{C}$ and polyurethane), biopolymers (e.g., alginate), hydrogels (e.g., Polyvinyl alcohol), smart polymers (e.g., poly-N-isopropylacrylamide) and inorganic supports (e.g., alumina, silica and zeolites) have been used in immobilization of enzymes (Katchalski-Katzir and Kraemer, 2000; Kirk and Christensen, 2002; Temino et al., 2005; Lutz et al., 2006; Awang et al., 2007; Sheldon, 2007). Biopolymers are one of the most applied supports for immobilizing enzymes, includes two types of mainly water insoluble proteins such as gelatin and albumin and polysaccharides such as starch, alginate and chitosan (Gorecka and Jastrzebska, 2011).

\subsection{Enzyme Immobilization Techniques}

Immobilization often stabilizes structure of the enzymes, thereby allowing their applications even under harsh environmental conditions of $\mathrm{pH}$, temperature and organic solvents and thus enable their uses at high temperatures in non aqueous enzymology and in the fabrication of biosensor probes. Different methods for the immobilization of enzymes have been critically reviewed. 


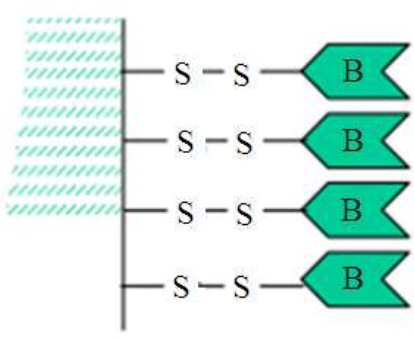

Disulfide bonds

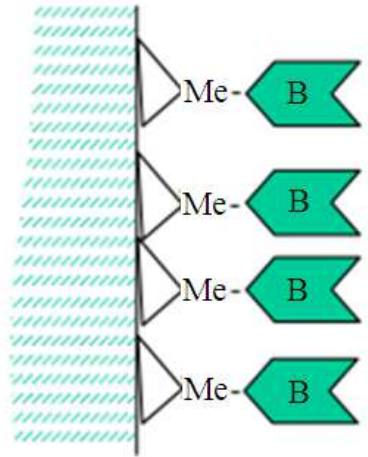

Metal or chelation

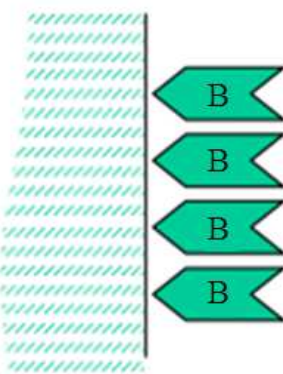

Adsorption

Fig. 1. Reversible methods of enzyme immobilization. B: Biocatalyst (Enzyme) Source: Gorecka and Jastrzebska (2011)

These methods are divided into two main categories namely; reversible and irreversible immobilization (Sheldon, 2007). Adsorption, disulphide bonding and chelation or metal binding are the reversible methods for enzyme immobilization (Gorecka and Jastrzebska, 2011).

Adsorption is the elementary and probably the simplest method of immobilization. This method is based on weak forces (e.g., van der Waals), however still enabling an efficient binding process. A wide range of both organic and inorganic materials can be used as a support in this method (Cetinus et al., 2007). Disulphide binding may be seen as a variation of covalent bonding, as there are stable covalent bonds formed between activated support and free thiol group (e.g., on cysteine) in the biocatalyst (Gulla et al., 2004). Chelation is based on the ability of the side chains of certain amino acids (e.g., histidine, tryptophan, tyrosine, cysteine and phenylalanine) to substitute weakly bonded ligands in the metal ions that have been immobilized by chelating group covalently bound to a solid support (Gorecka and Jastrzebska, 2011). Schematics of reversible enzyme immobilization methods are shown in Fig. 1.

Covalent bonding, entrapment, encapsulation and cross linking, fall into the irreversible enzyme immobilization methods. Covalent bonding is one of the most widely used methods for enzymes immobilization. Popularity of this approach is mainly connected with the stability of the bonds formed between the enzyme and the support, which prevents enzyme release into the environment (Sheldon, 2007). Entrapment is based on incorporating enzymes into the lattices of a semi permeable gel or enclosing the enzymes in a semi permeable polymer membrane (Lei et al., 2003).
Encapsulation is similar to entrapment. In this process, enzymes are restricted by the membrane walls (usually in a form of a capsule) (Ma et al., 2009; Briones and Sato, 2010). Cross linking method is widely used to immobilize enzymes and is based on intermolecular cross linking of enzymes by bi-functional or multi functional reagents (Seo et al., 2012). In fact, this method does not require a support and this is the advantage of this method. Immobilization of an enzyme on a carrier often leads to the loss of more than $50 \%$ native activity, specially at high enzyme loadings. The design of carrier bound immobilized enzymes also relies largely on laborious and time consuming trial and error experiments, because of the lack of guidelines that link the nature of a selected carrier to the performance expected for a given application (Sheldon, 2007; Spahn and Minteer, 2008). Schematics of irreversible enzyme immobilization techniques are shown in Fig. 2.

\subsection{Chitosan}

Chitin is a copolymer of N-acetyl-D-glucosamine and D-glucosamine units linked with $\beta-(1-4)$ glycosidic bond, where $\mathrm{N}$-acetyl-d-glucosamine units are predominant in the polymeric chain (Agnihotri et al., 2004). The deacetylated form of chitin refers to chitosan (Lee et al., 2009). Basically, the process consists of deproteinization of the raw shell material with a dilute $\mathrm{NaOH}$ solution and decalcification with a dilute $\mathrm{HCl}$ solution. To result in chitosan, the obtained chitin is subjected to N-deacetylation by treatment with a $40-45 \%$ $\mathrm{NaOH}$ solution, followed by purification procedures (Krajewska, 2004). Thus, production and utilization of chitosan constitutes an economically attractive means of crustacean shell wastes disposal sought worldwide. 


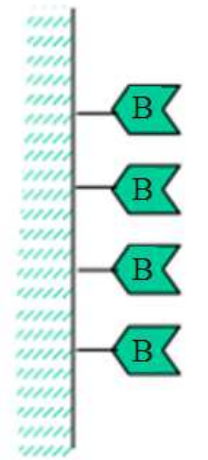

Covalent bonding

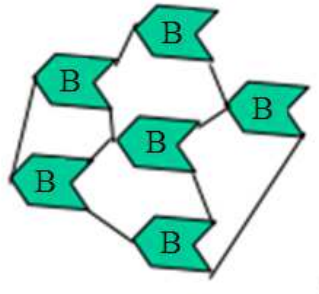

Cross linking

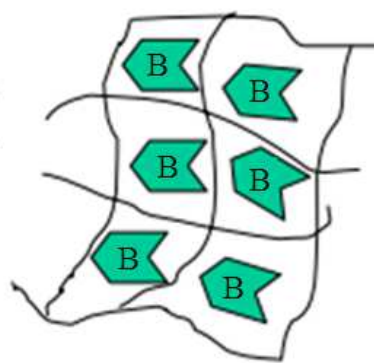

Entrapment

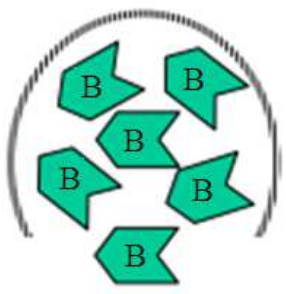

Encapsulation

Fig. 2. Irreversible methods of enzyme immobilization. B: Biocatalyst (Enzyme) Source: Gorecka and Jastrzebska (2011)

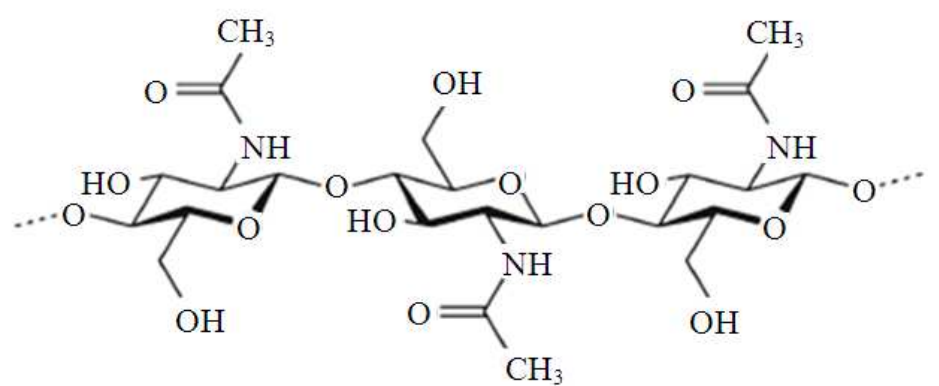

(a)

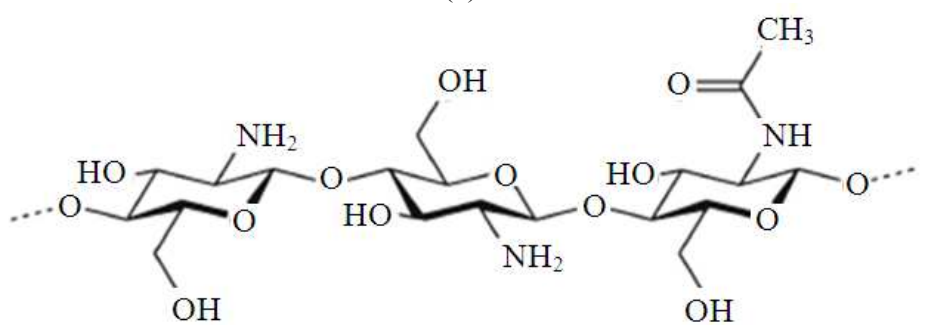

(b)

Fig. 3. Chemical structure of chitin (a) chitosan (b) Source: Krajewska (2004)

These renewable resources are found in many naturally occurring organisms (e.g., fungi and yeast) and is the principal component in the exoskeleton of sea crustaceans such as crabs, shrimps, lobsters and krills (Shi et al., 2011b). Chitosan represents long chain polymers having molecular mass up to several million Daltons. Chitosan is relatively reactive natural biopolymer due to presence of reactive amino and hydroxyl functional groups in its structure and can be produced in various forms such as powder, gels and films, sponges, intragastric floating tablets and especially spherical micro and nanoparticles (Agnihotri et al., 2004;
Racovita et al., 2008). If degree of deacetylation and molecular weight of chitosan can be controlled, then it would be a material of choice for developing micro and nanoparticles. Chitosan has ability to control the release of active agents and avoid the use of hazardous organic solvents while fabricating particles since it is soluble in aqueous acidic solution. It is a linear polyamine containing a number of free amine groups that are readily available for cross linking and its cationic nature allows for ionic cross linking with multivalent anions. Chitosan has mucoadhesive character, which increases residual time at the site of absorption (Agnihotri et al., 
2004; Grenha et al., 2005; Kim et al., 2008; Racovita et al., 2008). Chemical structures of chitin and chitosan are shown in Fig. 3.

\subsection{Applications of Chitosan}

Chitosan due to its unique physico-chemical and biological properties is an attractive material for use in various applications (Sorlier et al., 2001; Yang et al., 2010). These properties include: biodegradability, lack of toxicity, antibacterial and antifungal effects, wound healing acceleration and immune system stimulation (Shi et al., 2011a). Because of excellent biological and physico-chemical properties of chitosan, it has the ability to bind to particular materials including cholesterols, fats, proteins, metal ions and even tumor cells (Grenha et al., 2005). This allows chitosan to be used as a chelating agent in various applications.

Over the last decade, a number of potential products based on chitosan have been increasingly produced and applied in several areas such as: waste water treatment, due to its high adhesive and insolubility properties (e.g., removal of heavy metal ions and membrane purification processes); food industries (e.g., anticholesterol and fat binding, preservative, packaging material and animal feed additive); agriculture (e.g., seed and fertilizer coating, controlled agrochemical release); pulp and paper industries, because of its wet strength to paper (e.g., surface treatment, photographic paper) and cosmetics and toiletries due to its fungicidal and fungistatic properties (e.g., moisturizer, body creams, bath lotion) (Krajewska, 2004; Nakorn, 2008; Azeredo, 2009). Fibers made of chitosan are useful as absorbable sutures and wound dressing materials (Nakajima et al., 1984). Chitosan has also important applications in photography due to its resistance to abrasion, optical characteristics and film forming ability (Nuzzarelli et al., 1997). Due to its unique molecular structure, chitosan has an extremely high affinity for many classes of dyes, including disperse, direct, reactive, acid, vat, sulfur and naphthol dyes (Krajewska, 2005).

Chitosan ability to development of drug delivery systems is one of the most well known of its characteristics. Different types of chitosan made drug carriers have been conceived for various administration routes, such as oral, nasal, transdermal, parenteral, vaginal, cervical and rectal due to its biocompatibility, biodegradability and ecological safety (Racovita et al., 2008). Tissue engineering is an important therapeutic strategy for present and future medicine. Recently, functional biomaterial researches have been directed towards the development of improved scaffolds for regenerative medicine. Chitosan and its derivatives are promising candidates as a supporting material for tissue engineering applications owing to their porous structure, gel forming properties, ease of chemical modification, high affinity to in vivo macromolecules and so on (Kim et al., 2008). Moreover, it is one of the most promising immobilization matrices with excellent characteristics as a support matrix for enzyme immobilization (Nakorn, 2008).

\subsection{Immobolized Enzymes onto Chitosan}

Chitosan has shown favorable biocompatibility characteristics, as well as the ability to increase membrane permeability (Nakorn, 2008). Moreover, it is one of the most promising immobilization matrices due to an excellent membrane forming ability, good adhesion, low cost, low immunogenicity and nontoxicity, high mechanical strength and hydrophilicity as well as the improvement of stability (Dutta et al., 1997; Monteiro and Airoldi, 1999; Kumar et al., 1999; Vazquez-Duhalt et al., 2001; Colonna et al., 2008). These properties have prompted extensive applications of chitosan as a matrix for enzyme immobilization. In fact, polycationic nature of chitosan and presence of large primary amine groups in its chemical structure (Fig. 3b) make it potentially useful in immobilization of various enzymes (Fang et al., 2009). Results of several studies have been shown that after selection of suitable enzyme immobilization method, chitosan reactive amino and hydroxyl groups offer a good enzyme coupling efficiency (Luo et al., 2005; Biro et al., 2009; Yang et al., 2010).

Chitosan has been extensively used in immobilization of various enzymes groups because of its many characteristics like improved resistance to chemical degradation, avoiding disturbance of metal ions to enzyme and antibacterial property (Tang et al., 2006). Simsek-Ege et al., 2002; Vaillant et al., 2000) used chitosan to immobilize carbonic anhydrase and pectin lyase, respectively, which both of them are classified in lyase enzymes group. Applications of chitosan in immobilization of oxidoreductase, hydrolase and transferase enzymes are summarized in Table 1-3, respectively.

\subsection{Chitosan Nanoparticle}

In recent decades, nanostructured materials have attracted much attention because of their unique properties and interesting applications. Nanotechnology is the ability to work on a scale of about 1-100 nm in order to understand, create, characterize and use material structures, devices and systems with new properties derived from their nanostructures (Azeredo, 2009). 
Table 1. Some of immobilized oxidoreductases onto chitosan

\begin{tabular}{|c|c|c|c|}
\hline Enzeme & Support & Type of immobilization & Reference \\
\hline Alanine dehydrogenase & Chitosan beads & Covalent binding with $\mathrm{G}$ & Kiba et al. (1993) \\
\hline Alcohol dehydrogenase & Chitosan beads & Covalent binding with $\mathrm{G}$ & Soni et al. (2001) \\
\hline Alcohol oxidase & Chitosan beads & Covalent binding with $\mathrm{G}$ & Taniai et al. (2001) \\
\hline Catalase & F3GA attached-chitosan beads & Adsorption on support & Cetinus et al. (2007) \\
\hline Galactose oxidase & Chitosan membrane & Covalent binding with $\mathrm{G}$ & Wang et al. (2003) \\
\hline Glucose oxidase & Chitosan capsules & Micro encapsulation & Briones and Sato (2010) \\
\hline Glutamate dehydrogenase & Chitosan membrane & Covalent binding with $\mathrm{G}$ & Petach and Driscoll (1994) \\
\hline Glutamate oxidase & Chitosan membrane & Covalent binding with $\mathrm{G}$ & Wang et al. (2003) \\
\hline Horseradish peroxidase & Chitosan membrane & Covalent binding with $\mathrm{G}$ & Lei et al. (2003); Monier et al. (2010) \\
\hline Laccase & $\begin{array}{l}\text { Magnetic chitosan } \\
\text { microspheres }\end{array}$ & $\begin{array}{l}\text { Adsorption followed by } \\
\text { cross linking with } G\end{array}$ & Jiang et al. (2005) \\
\hline Lactate oxidase & Chitosan-enzyme beads & Gel inclusion & Wei et al. (2003) \\
\hline Leucine dehydrogenase & Chitosan capsules & Micro encapsulation & Ma et al. (2009) \\
\hline Octopine dehydrogenase & Chitosan beads & Covalent binding with $\mathrm{G}$ & Shin et al. (1998) \\
\hline Oxalate oxidase & Chitosan powder & $\begin{array}{l}\text { Adsorption followed by } \\
\text { cross linking with } G\end{array}$ & Ramakrishnan et al. (1997) \\
\hline Putrescine oxidase & Chitosan beads & Covalent binding with $\mathrm{G}$ & Okuma et al. (1992) \\
\hline Sulfite oxidase & Chitosan-PHEMA membrane & Adsorption on support & $\mathrm{Ng}$ et al. (1998) \\
\hline Uricase & Chitosan membrane & $\begin{array}{l}\text { Covalent binding with } \\
\text { agents other than } G\end{array}$ & Yao et al. (2003) \\
\hline Xanthine oxidase & Chitosan beads & Covalent binding with $\mathrm{G}$ & Park and Kim (1999) \\
\hline
\end{tabular}

\section{G: Glutaraldehyde}

Table 2. Some of immobilized hydrolases onto chitosan 
Table 3. Some of immobilized transferases onto chitosan

\begin{tabular}{llll}
\hline Enzyme & Support & Type of immobilization & Reference \\
\hline Cyclodextrin glycosyltransferase & Chitosan powder & Adsorption on support & Sobral et al. (2002) \\
Limonoid glucosyltransferase & Chitosan powder & Covalent binding with G & Karim and Hashinaga (2002) \\
Nucleoside phosphorylase & Chitosan beads & Covalent binding with G & Park and Kim (1999) \\
Transglutaminase & Chitosan beads & Covalent binding with G & Nonaka et al. $(1996)$ \\
W-transaminase & Chitosan beads & Covalent binding with G & Yi et al. $(2007)$ \\
\hline G: & &
\end{tabular}

G: Glutaraldehyde

Reducing the particle size of materials is an effective method for improving their properties. Nanoparticles have proportionally larger surface area and consequently more surface atoms than their microscale counterpart, which in turn affects their physico-chemical, optical, catalytic and other reactive properties (Rai et al., 2009). In polymer composites conjugated with nanoparticles, a uniform dispersion of nanoparticles leads to a very large matrix/filler interfacial area, which changes the molecular mobility, the relaxation behavior and the consequent thermal and mechanical properties of the materials (Azeredo, 2009). In contrast to other biopolymers, chitosan is a hydrophilic polymer with positive charge that comes from weak basic groups, which give it special characteristics from the technological point of view (Lopez-Leon et al., 2005). Recently, chitosan nanoparticles have attracted great attention in several fields due to their unique physicochemical and biological properties (Azeredo, 2009; Racovita et al., 2008; Shi et al., 2011a).

\subsection{Chitosan Nanoparticles Preparation Methods}

Several methods have been used to prepare chitosan nanoparticulate. The selection of any of these methods depends on shape and particle size requirements (Agnihotri et al., 2004). Emulsion cross linking, emulsion-droplet coalescence, coacervation/precipitation, ionotropic gelation, reverse micelles, template polymerization and molecular self assembly are the main preparation methods of chitosan nanoparticles (Agnihotri et al., 2004; Lopez-Leon et al., 2005; Tang et al., 2006; Biro et al., 2008; Shi et al., 2011a).

In emulsion cross linking method, the reactive functional amine group of chitosan crosses link with aldehyde groups of the cross linking agent. In fact, chitosan solution is emulsified in oil phase (water-in-oil emulsion) and the aqueous droplets are stabilized using a suitable surfactant. The stable emulsion is then reacted with an appropriate cross linking agent such as glutaraldehyde to stabilize the chitosan droplets. The nanoparticles are then washed and dried (Agnihotri et al., 2004).
Ionotropic gelation method is commonly used to prepare chitosan nanoparticles. This method is based on the electrostatic interactions between the chitosan amine group and a polyanion such as tripolyphosphate. In this method chitosan is dissolved in water or in weak acidic medium. This solution is then added drop wise under constant stirring to the solutions containing other counter ions. Due to the complexation between oppositely charged species, chitosan undergo ionic gelation and precipitate to form spherical nanoparticles (Racovita et al., 2008). Much researches have been focused on the preparation of chitosan nanoparticles using inotropic gelation method (Grenha et al., 2005; Lopez-Leon et al., 2005; Gan and Wang, 2007; Tang et al., 2006; Biro et al., 2008).

In coacervation/precipitation method, the chitosan solution is spraying into sodium hydroxide, $\mathrm{NaOH}$ methanol or ethanediamine alkaline solutions using compressed air, which in turn originates coacervated chitosan droplets in the form of nanoparticles (Shi et al., 2011a). Emulsion-droplet coalescence method involves both emulsion cross linking and precipitation. A stable emulsion containing the aqueous chitosan solution in oil and a second emulsion, containing a $\mathrm{NaOH}$ solution, is produced. By mixing the both emulsions under high speed stir, droplets of each emulsion collide at random, coalesce and finally precipitate as small size particles (Shikata et al., 2002).

In the reverse micelles method, a surfactant is dissolved in organic solvent to prepare reverse micelles. The aqueous phase containing the chitosan is added to this emulsion with constant vortexing and the nanoparticles forms in the core of the reverse micelles (Agnihotri et al., 2004).

In template polymerization, chitosan is firstly dissolved in an acrylic monomer solution under magnetic stirring. Due to the electrostatic interaction, the negatively charged acrylic monomers align along the chitosan molecules. After complete dissolution of chitosan, the polymerization is started by adding the initiator $\left(\mathrm{K}_{2} \mathrm{~S}_{2} \mathrm{O}_{8}\right)$ under stirring at $70^{\circ} \mathrm{C}$. The complete polymerization leads to the appearance of an opalescent solution, indicating the nanoparticles formation (Fang et al., 2009; Shi et al., 2011a). 
Molecular self assembly is based on cationic and hydrophobic properties of chitosan. This method is characterized by diffusion followed by specific association of molecules through non-covalent interactions, including electrostatic and/or hydrophobic associations (Ichikawa et al., 2005).

\subsection{Chitosan Nanoparticles Applications}

Chitosan nanoparticles are natural materials with excellent physico-chemical, antimicrobial and biological properties, which make them a superior environmentally friendly material and they possess bioactivity that does not harm humans. Due to these unique properties, chitosan nanoparticles are being used in a vast array of widely different products and applications, ranging from pharmaceutical, tissue engineering and food packaging to biosensing, enzymes immobolization and waste water treatment.

The potential use of chitosan nanoparticles as carriers has led to the development of many different colloidal delivery vehicles. The main advantages of this kind of systems lie in their capacity to cross biological barriers, to protect macromolecules, such as peptides, proteins, oligonucleotides and genes from degradation in biological media and to deliver drugs or macromolecules to a target site with following controlled release (LopezLeon et al., 2005; Shi et al., 2011a). Chitosan nanoparticles have frequently used as a controlled release drug carrier for gene transfer in artificial organs and for immune prophylaxis. In addition, chitosan nanoparticles have been used to improve the strength and washability of textiles and to confer antibacterial effects (Panyam and Labhasetwar, 2003; Mansouri et al., 2004). Several researches have been demonstrated that chitosan nanoparticles are able to improve drug bioavailability, modify pharmacokinetics and protect the encapsulated drugs (Janes et al., 2001; Shi et al., 2011b).

In tissue engineering, chitosan nanoparticles improve transmucosal permeability enhancing transport through the paracellular pathway due to good bio and mucoadhesive properties of the nanoparticles and to an induced structural reorganization of tight junctionassociated proteins (Peppas and Huang, 2004).

During the past decade, there was an increasing interest to develop and use bio-based active films which are characterized by antimicrobial and antifungal activities in order to improve food preservation. Chitosan based films have attracted serious attention in food preservation and packaging technology. This is mainly due to the excellent film forming and gas barrier properties of chitosan and its high antimicrobial activity against pathogenic and spoilage microorganisms, including fungi and bacteria (Malmiri et al., 2011).
Addition of chitosan nanoparticles into the coating and film formulations, improve film tensile properties and their permeability towards water vapor and simple gases (e.g., oxygen and carbon dioxide) (Moura et al., 2009).

Electrochemical biosensor has been considered as the best choice for the in situ monitoring of active compounds (e.g., phenolic) by virtue of its high sensitivity, simple instrumentation, low production cost and promising response speed (Lu et al., 2010). Excellent membrane forming ability of chitosan nanoparticles and their small response time and high sensitivity and stability (due to their high surface to volume ratio), low cost and hydrophilicity making them suitable for biosensor applications that are mostly concerned with working of enzymes for detection mechanisms (Nakorn, 2008).

Arsenic, molybdenum, lead and copper widely used in industries and are released through industrial waste water. Sorption processes are found to be capable of adsorbing large number of metal ions from contaminated waste water. In many studies such as adsorption of metals (e.g., copper and zinc), polymer supported nanoparticles has been prepared and used for selective removal of metal compounds and target metal contaminants (Xu and Du, 2003). Chitosan due to its high hydrophilicity and presence of a large number of hydroxyl and amino groups with high activity as adsorption sites is found to be more efficient for the removal of metals such as uranium, copper, vanadium and molybdenum (Guibal et al., 1994; Ngah et al., 2011). Nowadays, chitosan nanoparticles have been used effectively in waste water treatment to remove toxic metal ions such as arsenic (Anto and Annadurai, 2012).

Nano carriers can be effectively controlled by the application of nanotechnology. The catalytic efficiency and stability property of immobilized enzymes can be greatly improved. Furthermore, immobilization rate of enzyme can be improved using chitosan nanoparticles (Tang et al., 2006; Wu et al., 2009; Kalkan et al., 2012).

\subsection{Chitosan Nanoparticles as Enzyme Immobilization Support}

The results of immobilization, including the performance of immobilized enzymes, strongly depend on the properties of supports, which are usually referred to as material types, compositions and structures (Wang et al., 2009). Chitosan is known as an ideal support material for enzyme immobilization because of its many characteristics like improved resistance to chemical degradation and avoiding disturbance of metal ions to enzyme (Vazquez-Duhalt et al., 2001; Yang et al., 2010). 
Table 4. Some of immobilized enzymes onto chitosan nanoparticles

\begin{tabular}{|c|c|c|c|}
\hline Enzyme & Support & Preparation method & Reference \\
\hline Alcohol dehydrogenase & $\mathrm{Fe}_{3} \mathrm{O}_{4}-$ chitosan nanoparticles & Covalent binding with glutaraldehyde & Li et al. (2008) \\
\hline$\beta$-d- Galactosidase & $\mathrm{Fe}_{3} \mathrm{O}_{4}-$ chitosan nanoparticles & Covalent binding with glutaraldehyde & Pan et al. (2009) \\
\hline$\beta$-Galactosidase & Chitosan nanoparticles & $\begin{array}{l}\text { Precipitation, emulsion cross linking, } \\
\text { ionic gelation }\end{array}$ & Biro et al. (2008) \\
\hline Glucoamylase & $\mathrm{Fe}_{3} \mathrm{O}_{4}-$ chitosan nanoparticles & Ionic adsorption & Wang et al. (2012) \\
\hline Glucose oxidase & Chitosan nanoparticles & Covalent binding & Nakorn (2008) \\
\hline Laccase & Chitosan nanoparticles & Reversed phase suspension & Fang et al. (2009) \\
\hline 1-Laccase & $\mathrm{Fe}_{3} \mathrm{O}_{4}-$ chitosan nanoparticles & Ionic adsorption and covalent binding & Kalkan et al. (2012) \\
\hline Lipase & $\mathrm{Fe}_{3} \mathrm{O}_{4}-$ chitosan nanoparticles & Cross linking with trypolyphosphate & Wu et al. (2009) \\
\hline Neutral proteinase & Chitosan nanoparticles & Ionic gelation & Tang et al. (2006) \\
\hline Pullulanase & $\mathrm{Fe}_{3} \mathrm{O}_{4}-$ chitosan nanoparticles & Photochemistry in aqueous suspension & Zhang et al. (2009) \\
\hline Trypsin & $\begin{array}{l}\text { Linolenic acid-modified } \\
\text { chitosan nanoparticles }\end{array}$ & Covalent binding with glutaraldehyde & Liu et al. (2005) \\
\hline
\end{tabular}

Enzymes have been immobilized onto chitosan supports with different particle size. For practical purposes, carrier beads with size falling into millimeter range are mainly used (Guo et al., 2003; Krajewska, 2004; Shi et al., 2011b).

Under the scale of nano, nanomaterials have characteristics, such as magnetism and large surface area to volume ratio. These characteristics are in favour of immobilization of the enzymes (Tang et al., 2006). Recent studies indicated that the performance of enzyme immobilization onto chitosan nanoparticles is higher than that of the biocatalyst immobilized onto chitosan microparticles (Biro et al., 2008; Nakorn, 2008). The result can be related to better distribution of the enzyme onto the support due to high specific surface area and numerous active functional groups available for fixing the enzyme molecules (Tang et al., 2006).

Activity of immobilized enzymes strongly affects by size and size distribution of the support particles. Specific surface available to bind the applied enzyme and the contacting area with the substrate during a reaction mainly depends on particle size. Therefore, a lot of efforts were made to minimize the particle size and maximize the specific surface area (Biro et al., 2009). In addition, the physical characteristics of nanoparticles such as enhanced diffusion and particle mobility can impact inherent catalytic activity of attached enzymes (Jia et al., 2003).

Biro et al. (2008) indicated that the activity of $\beta$ galactosidase immobilized onto chitosan nanoparticles was higher than that of the biocatalyst immobilized onto chitosan micro and macroparticles. Research studies have also indicated that the stability of immobilized enzymes onto chitosan nanoparticles drastically affects by method of chitosan nanoparticles preparation and type of surfactant (Tang et al., 2006; Biro et al., 2008).
Immobolization of enzymes onto biopolymers nanoparticles has shown some benefits like improving their stability to $\mathrm{pH}$ and temperature, resistance to proteases and other denaturing compounds, as well as an adequate environment for their repeated use or controlled release (Fang et al., 2009). In the last decades, immobilized enzymes onto nanoparticles have been also considered for biosensors and food packaging applications (Nakorn, 2008; Azeredo, 2009). Applications of chitosan nanoparticles in immobilization of some enzymes are summarized in Table 4.

Liu et al. (2005) studied trypsin immobilized on linolenic acid-modified chitosan nanoparticles using glutaraldehyde as cross linker. Their results indicated that the kinetic constant value $\left(\mathrm{K}_{\mathrm{m}}\right)$ of trypsin immobilized on nanoparticles $\left(71.9 \mathrm{mg} \mathrm{mL}^{-1}\right)$ was higher than that of pure trypsin $\left(50.2 \mathrm{mg} \mathrm{mL}^{-1}\right)$. Tang et al. (2006) used Chitosan nanoparticles as support to immobilize and protect activity of neutral proteinase. Their results indicated that chitosan nanoparticles could improve $13.17 \%$ of neutral proteinase activity than that of free neutral proteinase. Nakorn (2008) used glucose oxidase immobilized onto chitosan nanoparticles in biosensor for glucose determination. The coated electrode with immobilized glucose oxidase exhibits a rapid and sensitive current response for the changes of glucose concentration in the prepared solutions and indicates the excellent electrocatalytic behaviour of the electrode. Li et al. (2008) immobilized Saccharomyces Cerevisiae Alcohol Dehydrogenase (SCAD) to magnetic $\mathrm{Fe}_{3} \mathrm{O}_{4}$-chitosan nanoparticles. For reduction of phenylglyoxylic acid by immobilized SCAD, the kinetic analysis data indicated that the immobilized SCAD retained $48.77 \%$ activity of its original activity. Furthermore, the immobilized SCAD enhanced thermal 
stability and good durability in the repeated use after recovered by magnetic separations. Fang et al. (2009) prepared magnetic chitosan nanoparticles and then immobilized laccase onto them. The immobilized laccase exhibited an appreciable catalytic capability (480 units · $\mathrm{g}^{-1}$ support) and had good storage stability and operation stability. The $\mathrm{K}_{\mathrm{m}}$ of immobilized and free laccase for ABTS (2, 2' -azino-bis (3-ethyl benzthiazoline-6sulfunate)) were 140.6 and $31.1 \mu \mathrm{M}$ in phosphate buffer (0.1 M, pH 3.0) at $37^{\circ} \mathrm{C}$, respectively. Pan et al. (2009) developed a novel and efficient immobilization of $\beta$-dgalactosidase by using magnetic $\mathrm{Fe}_{3} \mathrm{O}_{4}$-chitosan nanoparticles. The immobilized $\beta$-d-galactosidase showed the same or even higher activity in wider ranges of temperature and $\mathrm{pH}$ than that of its free form. In addition, the immobilized enzyme could be stored for a long time with little activity loss. Furthermore, the immobilized enzyme retained $92 \%$ of its initial activity after successively utilization for 15 cycles. Wu et al. (2009) prepared magnetic $\mathrm{Fe}_{3} \mathrm{O}_{4}$-chitosan nanoparticles and immobilized lipase onto them. The immobilization of lipase onto the nanoparticles showed good loading ability and little loss of enzyme activity and the stability of the catalyst was very good. In fact, it only lost $12 \%$ of enzyme activity after five batches. Zhang et al. (2009) prepared magnetic chitosan beads (with mean particle size of $50 \pm 3 \mathrm{~nm}$ ) and immobilized pullulanase on them. Results indicated that the kinetic constant value $\left(\mathrm{K}_{\mathrm{m}}\right)$ of immobilized pullulanase was three times higher than that of free pullulanase. However, the thermal and operational stabilities of immobilized pullulanase were improved greatly. Kalkan et al. (2012) immobilized 1laccase onto chitosan-coated magnetic nanoparticles by adsorption and covalent binding after activating the hydroxyl groups of chitosan with carbodiimide or cyanuric chloride. The results indicated that the immobilized enzyme retained more than $71 \%$ of its initial activity at the end of 30 batch uses. Wang et al. (2012) immobilized glucoamylase onto $\mathrm{Fe}_{3} \mathrm{O}_{4}$-chitosan nanoparticles. The results from characterization and determination remarkably indicated that the immobilized glucoamylase obtained presents excellent storage stability, $\mathrm{pH}$ stability, reusability, magnetic response and regeneration of supports.

\subsection{Challenges in Applications of Nanoparticles to Immobilize Enzymes}

Application of nanoparticles in enzyme immobilization has been associated with two main disadvantages. The first is lower storage stability of immobilized enzyme onto nanoparticles as compared to that of the immobilized enzyme onto microparticles. This can be explained by the fact that nanoparticles are aggregated during the storage. In fact, if the nanoparticles are not stabilized, they try minimizing their surface energy by clustering together (Ren et al., 2011). Biro et al. (2008) indicated that the stability of BGalactosidase immobilized onto chitosan nanoparticles was lower than that of the biocatalyst immobilized onto chitosan micro and macroparticles. The second disadvantage of using nanoparticles to immobilize enzyme is difficult separation of them from the reaction mixture at the end of the biochemical process, due to their small size (Prakasham et al., 2010). In this case, suitable methods are necessary to apply to facilitate the separation of the catalyst particles. Therefore, the general use of nanosized catalysts in industrial biotechnology needs considerable research efforts yet (Biro et al., 2009).

To overcome these issues, nanosized magnetic particles have received increasing attention because of their larger specific surface area for the enzymes immobilization, their super paramagnetic nature for the reduction of self aggregation and easy separability from the reaction mixture by the application of a magnetic field (Wang et al., 2009; Demir et al., 2011). Magnetite $\left(\mathrm{Fe}_{3} \mathrm{O}_{4}\right)$, silica, Zinc Oxide $(\mathrm{ZnO})$, cellulose and chitosan are some of magnetic materials and their nanoparticles have been used to immobilize of various enzymes (Ansari and Husain, 2012).

Chitosan can be used as a material for magnetic carriers, since it has a variety of functional groups which can be tailored to specific application (Wu et al., 2009; Zhang et al., 2009). Additionally, glutaraldehyde cross linking is shown to be the simple and efficient method to immobilize enzymes. Glutaraldehyde can react with several functional groups of proteins and supports, such as amino groups. Each of glutaraldehydes is expected to form Schiff bases upon nucleophilic attack by the primary amino groups in enzymes and chitosan and due to the linkage formed by the Schiff base reaction, the enzyme stability is improved (Xie and Wang, 2012). Several methods have been developed to synthesize magnetic chitosan nanoparticles, such as microemulsion polymerization, emulsion polymerization and in situ polymerization (Zhang et al., 2009).

As clearly observed in Table 4, magnetic $\mathrm{Fe}_{3} \mathrm{O}_{4}-$ chitosan nanoparticles have been used as support to immobilize the most of enzymes. In fact, magnetic $\mathrm{Fe}_{3} \mathrm{O}_{4}$ nanoparticles tend to aggregate in liquid 
media due to the strong magnetic dipole-dipole attractions between particles. Thus, chitosan with specific functional groups have been used as stabilizer to modify and increase their stability (Pan et al., 2009). In addition to, coating magnetic $\mathrm{Fe}_{3} \mathrm{O}_{4}$ nanoparticles with chitosan can protect the nanoparticles against corrosion an also offers flexibility, favourable functional groups and features (e.g., their ability to fold into a globular state or structure) for various applications (Zhang et al., 2009).

Magnetic nano and micron sized particles with specific modifications are widely used in biomedical applications such as diagnostics, magnetic separation and purification of biomolecules. In fact, magnetic nanoparticles coated with biopolymers and immobilized with ligand were found to have promising characteristics for the application of these adsorbents in bioseparation processes, particularly in antibody, nucleic acids and enzymes purification (Berensmeier, 2006; Altintas et al., 2007).

Hritcu et al. (2009) prepared of magnetite/chitosan composite nanoparticles using co-precipitation followed by ionic gelation. The products can be used in bioseparation methods after attaching an application specific ligand to the surface amino groups. The production of core-shell $\mathrm{Fe}_{3} \mathrm{O}_{4}$-gold-chitosan nanocomposites has attracted much attention over the past several years as they can be used in biotechnological and biomedical areas, including biotargeting for cancer treatment, drug delivery, biodetection and downstream processing (e.g., the purification and bioseparation of biomolecules) (Salehizadeh et al., 2012).

\section{CONCLUSION}

Macro, micro and nanosized chitosan particles are suitable as carriers for enzyme immobilization. Chitosan nanoparticles due to their highest specific surface area are much proper for immobilization of higher amount of enzymes. As compared to chitosan macro and microparticles, higher activity values of immobilized enzyme onto chitosan nanoparticles is explained again by better distribution of the enzyme onto the larger surface area of nanoparticles. Higher magnetic property of chitosan nanoparticles reduces self aggregation of immobilized enzymes onto them and increases the stability of immobilized enzymes. Further studies will be needed explore the kinetic of immobilized enzymes onto chitosan nanoparticles. The immobilization of enzymes onto nanoparticles and the subsequent attachment of the nanoparticles onto an electrode is also an attractive alternative in biosensor researches and developments, especially in the case of magnetic nanoparticles which can be removed from the electrode by the action of magnetic fields.

\section{REFERENCES}

Abdel-Naby, M.A., 1993. Immobilization ofAspergillus niger NRC 107 xylanase and $\beta$-xylosidase and properties of the immobilized enzymes. Applied Biochem. Biotechnol., 38: 69-81. DOI: $10.1007 / \mathrm{BF} 02916413$

Abdel-Naby, M.A., A.M.S. Ismail, S.A. Ahmed and A.F. Abdel-Fattah, 1998. Production and immobilization of alkaline protease from Bacillus mycoides. Bioresource Technol., 64: 205-210. DOI: 10.1016/S0960-8524(97)00160-0

Agarwal, R. and M.N. Gupta, 1995. Evaluation of gluteraldehyde-modified chitosan as a matrix for hydrophobic interaction chromatography. Analytica Chim. Acta, 313: 253-257. DOI: 10.1016/00032670(95)00241-Q

Agnihotri, S.A., N.N. Mallikurjana and T.M. Aminabhavi, 2004. Recent advances on chitosanbased micro- and nanoparticles in drug delivery. $\mathrm{J}$. Controlled Release, 100: 5-28. DOI: 10.1016/j.jconrel.2004.08.010

Altintas, E.B., N. Tuzmen, N. Candan and A. Denizli, 2007. Use of magnetic poly(glycidyl methacrylate) monosize beads for the purification of lysozyme in batch system. J. Chromatography B: Analytical Technol. Biomed. Life Sci., 853: 105-113. PMID: 17400524

Altun, G.D. and S.A. Cetinus, 2007. Immobilization of pepsin on chitosan beads. Food Chem., 100: 964971. DOI: 10.1016/j.foodchem.2005.11.005

Ansari, S.A. and Q. Husain, 2012. Potential applications of enzymes immobilized on/in nano materials: A review. Biotechnol. Adv., 30: 512-521. PMID: 21963605

Anto, S.M. and G. Annadurai, 2012. Arsenic adsorption from aqueous solution using chitosan nanoparticle. Res. J. Nanosci. Nanotechnol., 2: 3145. DOI: 10.3923/rjnn.2012.31.45

Awang, R., M.R. Ghazuli and M. Basri, 2007. Immobilization of lipase from Candida rugosa on palm-based polyurethane foam as a support material. Am. J. Biochem. Biotechnol., 3: 163-166. DOI: $10.3844 /$ ajbbsp.2007.163.166

Azeredo, H.M.C.D., 2009. Nanocomposites for food packaging applications. Food Res. Int., 42: 12401253. DOI: 10.1016/j.foodres.2009.03.019 
Berensmeier, S., 2006. Magnetic particles for the separation and purification of nucleic acids. Applied Microbiol. Biotechnol., 73: 495-504. DOI: $10.1007 / \mathrm{s} 00253-006-0675-0$

Biro, E., A.S. Nemeth, C. Sisak, T. Feczko and J. Gyenis, 2008. Preparation of chitosan particles suitable for enzyme immobilization. J. Biochem. Biophys. Methods, 70: 1240-1246. PMID: 18155771

Biro, E., A.S. Nemeth, T. Feczko, J. Toth, C. Sisak and J. Gyenis, 2009. Three-step experimental design to determine the effect of process parameters on the size of chitosan microspheres. Chem. Eng. Process. Process Intensificat., 48: 771-779. DOI: 10.1016/j.cep.2008.10.001

Briones, A.V. and T. Sato, 2010. Encapsulation of Glucose Oxidase (GOD) in polyelectrolyte complexes of chitosan-carrageenan. Reactive Functional Polymers, 70: 19-27. DOI: 10.1016/j.reactfunctpolym. 2009.09.009

Cetinus, S.A., H.N. Oztop and D. Saraydın, 2007. Immobilization of catalase onto chitosan and cibacron blue F3GA attached chitosan beads. Enzyme Microbial. Technol., 41: 447-454. DOI: 10.1016/j.enzmictec.2007.03.014

Chen, J.P. and J.Y. Chen, 1998. Preparation and characterization of immobilized phospholipase A2 on chitosan beads for lowering serum cholesterol concentration. J. Mol. Catalysis B: Enzymatic, 5: 483-490. DOI: 10.1016/S1381-1177(98)00077-0

Colonna, C., B. Conti, P. Perugini, F. Pavanetto and T. Modena et al., 2008. Ex vivo evaluation of prolidase loaded chitosan nanoparticles for the enzyme replacement therapy. Eur. J. Pharmaceutics Biopharmaceutics, 70: 58-65. DOI: 10.1016/j.ejpb.2008.04.014

D'Auria, S., F. Pellino, F. La Cara, R. Barone and M. Rossi et al., 1996. Immobilization on chitosan of a thermophilic beta-glycosidase expressed in Saccharomyces cerevisiae. Applied Biochem. Biotechnol., 61: 157-166. DOI: $10.1007 / \mathrm{BF} 02785698$

Darias, R. and R. Villalonga, 2001. Functional stabilization of cellulase by covalent modification with chitosan. J. Chem. Technol. Biotechnol., 76: 489-493. DOI: $10.1002 /$ jctb.386

Demir, A.S., F.N. Talpur, S.B. Sopaci, G.W. Kohring and A. Celik, 2011. Selective oxidation and reduction reactions with cofactor regeneration mediated by galactitol-, lactate- and formate dehydrogenases immobilized on magnetic nanoparticles. J. Biotechnol., 252: 176-183. PMID: 21392547
Dutta, P.K., P. Viswanathan, L. Mimrot and M.N.V.R. Kumar, 1997. Use of chitosan-amine oxide gel as drug carriers. J. Polymer Mater., 14: 351-356.

Dwevedi, A. and A.M. Kayastha, 2009. Optimal immobilization of beta-galactosidase from Pea (PsBGAL) onto Sephadex and chitosan beads using response surface methodology and its applications. Bioresource Technol., 100: 2667-2675. PMID: 19195879

Fang, H., J. Huang, L. Ding, M. Li and Z. Chen, 2009. Preparation of magnetic chitosan nanoparticles and immobilization of laccase. J. Wuhan Univ. Technol. Mater. Sci. Ed., 24: 42-47. DOI: 10.1007/s11595009-1042-7

Gan, Q. and T. Wang, 2007. Chitosan nanoparticle as protein delivery carrier-Systematic examination of fabrication conditions for efficient loading and release. Colloids Surfaces B: Biointerfaces, 59: 2434. DOI: 10.1016/j.colsurfb.2007.04.009

Ge, S.J. and L.X. Zhang, 1996. The immobilized porcine pancreatic exopeptidases and its application in casein hydrolysates debittering. Applied Biochem. Biotechnol., 59: 159-165. DOI: 10.1007/BF02787817

Gorecka, E. and M. Jastrzebska, 2011. Immobilization techniques and biopolymer carriers. Biotechnol. Food Sci., 75: 65-86.

Grenha, A., B. Seijo and C. Remunan-Lopez, 2005. Microencapsulated chitosan nanoparticles for lung protein delivery. Eur. J. Pharmaceutical Sci., 25: 427-437. DOI: 10.1016/j.ejps.2005.04.009

Guibal, E., I. Saucedo, M. Jansson-Charrier, B. Delanghe and P. L. Cloirec, 1994. Uranium and vanadium sorption by chitosan and derivatives. Water Sci. Technol., 30: 183-190.

Gulla, K.C., M.D. Guoda, M.S. Thakur and N.G. Karanth, 2004. Enhancement of stability of immobilized glucose oxidase by modification of free thiols generated by reducing disulfide bonds and using additives. Biosensors Biotechnol., 19: 621625. DOI: 10.1016/S0956-5663(03)00258-6

Guo, M.L., Y.M. Jiang, Z.L. Ma and Y.L. Li, 1996. Hydrolytic characteristics of chitosan-immobilized As 1.398 neutral proteinase (from B. subtilis) to soybean protein. Food Chem., 55: 373-377. DOI: 10.1016/0308-8146(95)00137-9

Guo, Z., S. Bai and Y. Sun, 2003. Preparation and characterization of immobilized lipase on magnetic hydrophobic microspheres. Enzyme Microbial. Technol., 32: 776-782. DOI: 10.1016/S01410229(03)00051-6 
Hayashi, T. and Y. Ikada, 1991. Protease immobilization onto porous chitosan beads. J. Applied Polymer Sci., 42: 85-92. DOI: 10.1002/app.1991.070420110

Hou, X., B. Liu, X. Deng, B. Zhang and H. Chen et al., 2007. Covalent immobilization of glucose oxidase onto poly(styrene-co-glycidyl methacrylate) monodisperse fluorescent microspheres synthesized by dispersion polymerization. Analytical Biochem., 368: 100-110. PMID: 17562322

Hritcu, D., M.I. Popa, N. Popa, V. Badescu and V. Balan, 2009. Preparation and characterization of magnetic chitosan nanospheres. Turkish J. Chem., 33: 785-796. DOI: 10.3906/kim-0812-42

Hsieh, H.J., P.C. Liu and W.J. Liao, 2000. Immobilization of invertase via carbohydrate moiety on chitosan to enhance its thermal stability. Biotechnol. Lett., 22: 1459-1464. DOI: 10.1023/A: 1005602812037

Ichikawa, S., S. Iwamoto and J. Watanabe, 2005. Formation of biocopmpatible nanoparticles by selfassembly of enzymatic hydrolysates of chitosan and carboxymethyl cellulose. Biosc. Biotechnol. Biochem., 69: 1637-1642. PMID: 16195579

Janes, K.A., M.P. Fresneau, A. Marazuela, A. Fabra and M.J. Alonso, 2001. Chitosan nanoparticles as delivery systems for doxorubicin. J. Control Release, 73: 255-267. PMID: 11516503

Janssen, M.H.A., L.M.V. Langen, S.R.M. Pereira, F.V. Rantwijk and R.A. Sheldon, 2002. Evaluation of the performance of immobilized penicillin $G$ acylase using active site-titration. Biotechnol. Bioeng., 78: 425-432. PMID: 11948449

Jia, H., G. Zhu and P. Wang, 2003. Catalytic behaviors of enzymes attached to nanoparticles: The effect of particle mobility. Biotechnol. Bioeng., 84: 406-414. DOI: 10.1002/bit.10781

Jiang, D.S., S.Y. Long, J. Huang, H.Y. Xiao and J.Y. Zhou, 2005. Immobilization of Pycnoporus sanguineus laccase on magnetic chitosan microspheres. Biochem. Eng. J., 25: 15-23. DOI: 10.1016 /j.bej.2005.03.007

Kalkan, N.A., S. Aksoy, E.A. Aksoy and N. Hasirci, 2012. Preparation of chitosan-coated magnetite nanoparticles and application for immobilization of laccase. J. Applied Polymer Sci., 123: 707-716. DOI: 10. 1002/app.34504

Karim, M.R. and F. Hashinaga, 2002. Preparation and properties of immobilized pummelo limonoid glucosyltransferase. Process Biochem., 38: 809-814. DOI: $10.1016 / \mathrm{S} 0032-9592(02) 00233-9$
Katchalski-Katzir, E. and D.M. Kraemer, 2000. Eupergit ${ }^{\circledR}$ C, a carrier for immobilization of enzymes of industrial potential. J. Mol. Catalysis B: Enzymatic, 10: 157-176. DOI: 10.1016/S13811177(00)00124-7

Kayastha, A.M. and P.K. Srivastava, 2001. Pigeonpea (Cajanus cajan L.) urease immobilized on glutaraldehyde-activated chitosan beads and its analytical applications. Applied Biochem. Biotechnol., 96: 41-53. DOI: 10.1385/ABAB:96:13:041

Kiba, N., Y. Oyama and M. Furusawa, 1993. Determination of aliphatic amino acids in serum by HPLC with fluorimetric detection using coimmobilized enzyme reactor. Talanta, 40: 657-660. PMID: 18965682

Kilinc, A., S. Onal and A. Telefoncu, 2002. Stabilization of papain by modication with chitosan. Turkish J. Chem., 26: 311-316.

Kim, I.Y., S.J. Seo, H.S. Moon, M.K. Yoo and I.Y. Park et al., 2008. Chitosan and its derivatives for tissue engineering applications. Biotechnol. Adv., 26: 121. DOI: 10.1016/j.biotechadv.2007.07.009

Kirk, O. and M.W. Christensen, 2002. Lipases from Candida antarctica: Unique biocatalysts from a unique origin. Organic Process Res. Dev., 6: 446451. DOI: 10.1021/op0200165

Krajewska, B., 2004. Application of chitin-and chitosanbased materials for enzyme immobilization: A review. Enzyme Microbial. Technol., 35: 126-139. DOI: $10.1016 /$ j.enzmictec.2003.12.013

Krajewska, B., 2005. Membrane-based processes performed with use of chitin/chitosan materials. Separation Purification Technol., 41: 305-312. DOI: 10.1016/ j.seppur.2004.03.019

Kumar, M.N.V.R., P. Singh and P.K. Dutta, 1999. Effect of swelling on chitosan-amine oxide gel in extended drug delivery. Indian Drugs, 36: 393-398.

Kurita, K., 2001. Controlled functionalization of the polysaccharide chitin. Progress Polymer Sci., 26: 1921-1971. DOI: 10.1016/S0079-6700(01)00007-7

Lao, L., H. Tan, Y. Wang and C. Gao, 2008. Chitosan modified poly(l-lactide) microspheres as cell microcarriers for cartilage tissue engineering. Colloids Surfaces B: Biointerfaces, 66: 218-225. PMID: 18691852

Lee, D.W., H. Lim, H.N. Chong and W.S. Shim, 2009. Advances in chitosan material and its hybrid derivatives: A review. Open Biomater. J., 1: 10-20. 
Lee, K.H., P.M. Lee and Y.S. Siaw, 1992. Studies of 1phenyl-alanine production by immobilized aminoacylase in stabilized calcium alginate beads. $\mathrm{J}$. Chem. Technol. Biotechnol., 54: 375-382. DOI: $10.1002 /$ jctb.280540411

Lei, C.X., S.Q. Hu, G.L. Shen and R.Q. Yu, 2003. Immobilization of horseradish peroxidase to a nano$\mathrm{Au}$ monolayer modified chitosan-entrapped carbon paste electrode for the detection of hydrogen peroxide. Talanta, 59: 981-988. DOI: 10.1016/S0039-9140(02)00641-0

Lei, Z. and S. Bi, 2007. The silica-coated chitosan particle from a layer-by-layer approach for pectinase immobilization. Enzyme Microbial. Technol., 40: 1442-1447. DOI: 10.1016/j.enzmictec.2006.10.027

Ley, Q., D. Holtmann, K.M. Mangold and J. Schrader, 2011. Immobilization of histidinetagged proteins on electrodes. Colloids Surfaces B: Biointerfaces, 88: 539-551. PMID: 21840689

Li, G.Y., K.L. Huang, Y.R. Jiang, D.L. Yang and P. Ding, 2008. Preparation and characterization of Saccharomyces cerevisiae alcohol dehydrogenase immobilized on magnetic nanoparticles. Int. J. Biol. Macromol., 42: 405-412. DOI: 10.1016/j.ijbiomac.2008.01.005

Li, J., J. Caib, L. Zhongc and Y. Dud, 2011. Immobilization of a protease on modified chitosan beads for the depolymerization of chitosan. Carbohydrate Polymers, 87: 2697-2705. DOI: 10.1016/j.carbpol.2011.11.062

Li, X., F. Gao, W. Wei, J.B. Qu and G.H. Ma et al., 2010. Pore size of macroporous polystyrene microspheres affects lipase immobilization. J. Mol. Catalysis B: Enzymatic, 66: 182-189. DOI: 10.1016/j.molcatb.2010.05.007

Liang, J.F., Y.T. Li and V.C. Yang, 2000. Biomedical application of immobilized enzymes. J. Pharmaceutical Sci., 89: 979-990. DOI: 10.1002/1520-6017(200008)89:8<979::AIDJPS2 $>3.0 . \mathrm{CO} ; 2-\mathrm{H}$

Liang, Z.P., Y.Q. Feng, S.X. Meng and Z.Y. Liang, 2005. Preparation and properties of urease immobilized onto glutaraldehyde cross-linked chitosan beads. Chinese Chem. Lett., 16: 135-138. Lin, H., H. Wang, C. Xue and M. Ye, 2002. Preparation of chitosan oligomers by immobilized papain. Enzyme Microbial. Technol., 31: 588-592. DOI: $10.1016 / \mathrm{S} 0141-0229(02) 00138-2$

Liu, C.G., X.G. Chen and H.J. Park, 2005. Selfassembled nanoparticles based on linoleic-acid modified chitosan: Stability and adsorption of trypsin. Carbohydrate Polymers, 62: 293-298. DOI: 10.1016/j.carbpol.2005.08.010
Lopez-Leon, T, E.L.S. Carvalho, B. Seijo, J.L. OrtegaVinuesa and D. Bastos-Gonzalez, 2005. Physicochemical characterization of chitosan nanoparticles: Electrokinetic and stability behavior. J. Colloid Interface Sci., 283: 344-351. DOI: 10.1016/j.jcis.2004.08.186

Lozinsky, V.I., I.Y. Galaev, F.M. Plieva, I.N. Savina and H. Jungvid et al., 2003. Polymeric cryogels as promising materials of biotechnological interest. Trends Biotechnol., 21: 445-451. DOI: 10.1016/j.tibtech.2003.08.002

Lu, L., L. Zhang, X. Zhang, S. Huan and G. Shen et al., 2010. A novel tyrosinase biosensor based on hydroxyapatite-chitosan nanocomposite for the detection of phenolic compounds. Analytica Chim. Acta, 665: 146-151. DOI: 10.1016/j.aca.2010.03.033

Luo, X.L., J.J. Xu, Q. Zhang, G.J. Yang and H.Y. Chen, 2005. Electrochemically deposited chitosan hydrogel for horseradish peroxidase immobilization through gold nanoparticles self-assembly. Biosensors Bioelect., 21: 190-196. DOI: 10.1016/j.bios.2004.07.029

Lutz, J.F., O. Akdemir and A. Hoth, 2006. Point by point comparison of two thermosensitive polymers exhibiting a similar LCST: Is the age of poly(NIPAM) over? J. Am. Chem. Soc., 128: 13046-13047. PMID: 17017772

Ma, L., W. Lu and J. Wen, 2009. Encapsulation of lactate dehydrogenase in carbon nanotube doped alginate-chitosan capsules. J. Mol. Catalysis B: Enzymatic, 56: 102-107. DOI: 10.1016/j.molcatb.2008.04.011

Magalhaes, J.M.C.S. and A.A.S.C. Machado, 2002. Array of potentiometric sensors for the analysis of creatinine in urine samples. Analyst, 127: 10691075. DOI: 10.1039/b201173e

Malmiri, J.H., A. Osman, C.P. Tan and R.A. Rahman, 2011. Development of an edible coating based on chitosan-glycerol to delay 'Berangan' banana (Musa sapientum cv. Berangan) ripening process. Int. Food Res. J., 18: 989-997.

Mansouri, S., P. Lavigne, K. Corsi, M. Benderdour and E. Beaumont et al., 2004. Chitosan-DNA nanoparticles as non-viral vectors in gene therapy: Strategies to improve transfection efficacy. Eur. J. Pharm. Biopharmaceutics, 57: 1-8. PMID: 14729076

Martino, A., C. Schiraldi, A. Di Lazzaro, I. Fiume and G. Spagna et al., 2000. Improvement of the flavour of Falanghina white wine using a purified glycosidase preparation from Aspergillus niger. Process Biochem., 36: 93-102. DOI: 10.1016/S00329592(00)00181-3 
Mateo, C., J.M. Palomo, G. Fernandez-Lorente, J.M. Guisan and R. Fernandez-Lafuente, 2007. Improvement of enzyme activity, stability and selectivity via immobilization techniques. Enzyme Microbial. Technol., 40: 1451-1463. DOI: 10.1016/j.enzmictec.2007.01.018

Miletic, N., A. Nastasovic and K. Loos, 2012. Immobilization of biocatalysts for enzymatic polymerizations: Possibilities, advantages, applications. Bioresource Technol., 115: 126-135. DOI: 10.1016/j.biortech.2011.11.054

Monier, M., D.M. Ayad, Y. Weia and A.A. Sarhanb, 2010. Immobilization of horseradish peroxidase on modified chitosan beads. Int. J. Biol. Macromol., 46: 324-330. DOI: 10.1016/j.ijbiomac. 2009.12.018

Monteiro, Jr. O.A.C. and C. Airoldi, 1999. Some studies of crosslinking chitosan-glutaraldehyde interaction in a homogeneous system. Int. J. Biol. Macromol., 26: 119-128. DOI: 10.1016/S0141-8130(99)00068-9

Moura, M.R.D., F.A. Aouada, R.J. Avena-Bustillos, T.H. McHugh and J.M. Krochta et al., 2009. Improved barrier and mechanical properties of novel hydroxypropyl methylcellulose edible films with chitosan/tripolyphosphate nanoparticles. J. Food Eng., 92: 448-453. DOI: 10.1016/j.jfoodeng.2008.12.015

Nakajima, M., K. Atsumi, K. Kifune, 1984. Development of Absorbable Sutures from Chitin. In: Chitin, Chitosan and Related Enzymes, Zikakis, J.P. (Ed.), Academic Press, Orlando, FL., ISBN-10: 0127809503, pp: 227-237.

Nakorn, P., 2008. Chitin nanowhisker and chitosan nanoparticles in protein immobilization for biosensor applications. J. Metals, Mater. Minerals, 18: 73-77.

Ng, L.T., Y.J. Yuan and H. Zhao, 1998. Natural polymer-based sulfite biosensor. Electroanalysis, 10: 1119-1124. 4109(199811)10:16<1119::AID-

ELAN1119>3.0.CO;2-U

Ngah, W.S.W., L.C. Teong and M.A.K.M. Hanafiah, 2011. Adsorption of dyes and heavy metal ions by chitosan composites: A review. Carbohydrate Polymers, 83: 1446-1456. DOI: 10.1016/j.carbpol.2010.11.004

Noda, T., S. Furuta and I. Suda, 2001. Sweet potato $\alpha-$ amylase immobilized on chitosan beads and its application in the semi-continuous production of maltose. Carbohydrate Polymers, 44: 189-195. DOI: 10.1016/S0144-8617(00)00226-5
Nonaka, M., A. Sawa, Y. Matsuura, M. Motoki and N. Nio, 1996. Deamidation of several food proteins using free and immobilized $\mathrm{Ca}^{2+}$-independent microbial transglutaminase. Biosci. Biotechnol. Biochem., 60: 532-533.

Nuzzarelli, R.A.A., C. Muzzarelli and M. Terbojevich, 1997. Chitin chemistry, upgrading a renewable resource. Carbohydrates Eur., 19: 10-17.

Okuma, H., H. Takahashi, S. Yazawa and S. Sekimukaki, 1992. Development of a system with double enzyme reactors for the determination of fish freshness. Analytica Chim. Acta, 260: 93-98. DOI: 10.1016/0003-2670(92)80131-P

Pan, C., B. Hu, W. Li, Y. Sun and H. Ye et al., 2009. Novel and efficient method for immobilization and stabilization of $\beta$-d-galactosidase by covalent attachment onto magnetic $\mathrm{Fe}_{3} \mathrm{O}_{4}-$ chitosannanoparticles. J. Mol. Catalysis B: Enzymatic, 61: 208-215. DOI: 10.1016/j.molcatb.2009.07.003

Panyam, J. and V. Labhasetwar, 2003. Biodegradable nanoparticles for drug and gene delivery to cells and tissue. Adv. Drug Delivery Rev., 55: 329-347. PMID: 12628320

Park, I.S. and N. Kim, 1999. Simultaneous determination of hypoxanthine, inosine and inosine 5'monophosphate with serially connected three enzyme reactors. Anal. Chim. Acta, 394: 201-210. DOI: $10.1016 / \mathrm{S} 0003-2670(99) 00435-3$

Peppas, N.A. and Y. Huang, 2004. Nanoscale technology of mucoadhesive interactions. Adv. Drug Delivery Rev., 56: 1675-1687. PMID: 15350296

Pereira, E.B., H.F.D. Castro, F.F.D. Moraes and G.M. Zanin, 2001. Kinetic studies of lipase from Candida rugosa. Applied Biochem. Biotechnol., 91-93: 739752. DOI: 10.1385/ABAB:91-93:1-9:739

Petach, H.H. and J. Driscoll, 1994. Transparent chitosan derivatives for the immobilization of glutamate dehydrogenase. Biotechnol. Bioeng., 44: 1018-1022. PMID: 18618922

Prakasham, R.S., G.S. Devi, C.S. Rao, V.S.S. Sivakumar and T. Satish et al., 2010. Nickel impregnated silica nanoparticle synthesis and their evaluation for biocatalyst immobilization. Applied Biochem. Biotechnol., 160: 1888-1895. PMID: 19685215

Racovita, S., S. Vasiliu, M. Popa and C. Luca, 2008. Polysaccharides based on micro-and nanoparticles obtained by ionic gelation and their applications as drug delivery systems. Revue Roumaine De Chimie, 54: 709-718. 
Rai, M., A. Yadav and A. Gade, 2009. Silver nanoparticles as a new generation of antimicrobials. Biotechnol. Adv., 27: 76-83. DOI: 10.1016/j.biotechadv.2008.09.002

Ramakrishnan, V., K.M. Lathika, S.J. D’Souza, B.B. Singh and K.G. Raghavan, 1997. Investigation with chitosan-oxalate oxidase-catalase conjugate for degrading oxalate from hyperoxaluric rat chyme. Indian J. Biochem. Biophys., 34: 373-378. PMID: 9491647

Ren, Y., J.G. Rivera, L. He, H. Kulkarni and D.K. Lee et al., 2011. Facile, high efficiency immobilization of lipase enzyme on magnetic iron oxide nanoparticles via a biomimetic coating. BMC Biotechnol., 11: 6371. DOI: $10.1186 / 1472-6750-11-63$

Salehizadeh, H., E. Hekmatian, M. Sadeghi and K. Kennedy, 2012. Synthesis and characterization of core-shell $\mathrm{Fe}_{3} \mathrm{O}_{4}$-gold-chitosan nanostructure. J. Nanobiotechnol., 10: 3-10. DOI: 10.1186/14773155-10-3

Salemi, Z., 2010. Tailor-made enzyme carriers: Preparation and use of adsorbents specifically designed to immobilize allosteric enzymes in activated conformation. Am. J. Biochem. Biotechnol., 6: 111-115. DOI: 10.3844/ajbbsp.2010.111.115

Samanta, D. and A. Sarkar, 2011. Immobilization of biomacromolecules on self-assembled monolayers: Methods and sensor applications. Chem. Soc. Rev., 40: 2567-2592. DOI: 10.1039/C0CS00056F

Schroder, M., E. von Lieres and J. Hubbuch, 2006. Direct quantification of intraparticle protein diffusion in chromatographic media. J. Phys. Chem. B, 110: 1429-1436. PMID: 16471694

Seo, D. J., Y. H. Janga, R. D. Park and W. J. Junga, 2012. Immobilization of chitinases from Streptomyces griseus and Paenibacillus illinoisensis on chitosan beads. Carbohydrate Polymers, 88: 391394. DOI: 10.1016/j.carbpol.2011.12.009

Seo, H., K. Itoyama, K. Morimoto, T. Takagishi and M. Oka et al., 1998. Spacer effects on enzymatic activity of bromelain immobilized onto porous chitosan beads. Eur. Polymer J., 34: 917-922. DOI: 10.1016/S0014-3057(97)00213-9

Sheldon, R.A., 2007. Enzyme immobilization: The quest for optimum performance. Adv. Synthesis Catalysis, 349: 1289-1307. DOI: 10.1002/adsc.200700082

Sheu, D.C., S.Y. Li, K.J. Duan and C.W. Chen, 1998. Production of galactooligosaccharides by $\beta$ galactosidase immobilized on glutaraldehyde-treated chitosan beads. Biotechnol. Techniques, 12: 273276. DOI: $10.1023 / \mathrm{A}: 1008894029377$
Shi, L.E., X.J. Fang, L.Y. Xing, M. Chen and D.S. Zhu et al., 2011a. Chitosan nanoparticles as drug delivery carriers for biomedical engineering. J. Chem. Soc. Pak., 33: 929-934.

Shi, L.E., Z.X. Tang, Y. Yi, J.S. Chen and W.Y. Xiong et al., 2011b. Immobilization of Nuclease p1 on ChitosanMicro-spheres. Chem. Biochem. Eng. Q., 25: 83-88.

Shikata, F., H. Tokumitsu, H. Ichikawa and Y. Fukumori, 2002. In vitro cellular accumulation of gadolinium incorporated into chitosan nanoparticles designed for neutron-capture therapy of cancer. Eur. J. Pharm. Biopharmaceutics, 53: 5763. PMID: 11777753

Shin, S.J., H. Yamanaka, H. Endo and E. Watanabe, 1998. Development of an octopine biosensor and its application to the estimation of scallop freshness. Enzyme Microbial. Technol., 23: 10-13. DOI: 10.1016/S0141-0229(98)00025-8

Silva, J.A., G.P. Macedoa, D.S. Rodriguesb, R.L.C. Giordanoc and L.R.B. Goncalves, 2012. Immobilization of Candida ntarctica lipase $\mathrm{B}$ by covalent attachment on chitosan-based hydrogels using different support activation strategies. Biochem. Eng. J., 60: 16-24. DOI: 10.1016/j.bej.2011.09.011

Simsek-Ege, F. A., G. M. Bond and J. Stringer, 2002. Matrix molecular weight cut-off for encapsulation of carbonic anhydrase in polyelectrolyte beads. J. Biomater. Sci. Polymer Ed., 13: 1175-1187. PMID: 12518798

Sobral, K.C.A., R.M.O. Rodrigues, R.D.D. Oliveira, F.F.D. Moraes and G.M. Zanim, 2002. Immobilization of cyclodextringlycosyltransferase (CGTase) from Bacillus firmus in commercial chitosan. J. Inclusion Phenomena Macrocyclic Chem., 44: 383-386. DOI: 10.1023/A:1023004927302

Soni, S., J.D. Desai and S. Devi, 2001. Immobilization of yeast alcohol dehydrogenase by entrapment and covalent binding to polymeric supports. J. Applied Polymer Sci., 82: 1299-1305. DOI: 10.1002/app.1964

Sorlier, P., A. Denuziere, C. Viton and A. Domard, 2001. Relation between the degree of acetylation and the electrostatic properties of chitin and chitosan. Biomacromolecules, 2: 765-772. PMID: 11710030

Spahn, C. and S.D. Minteer, 2008. Enzyme immobilization in biotechnology. Recent Patents Eng., 2 : $195-200$. DOI: $10.2174 / 187221208786306333$ 
Tang, Z.X., J.Q. Qian and L.E. Shi, 2006. Characterizations of immobilized neutral proteinase on chitosan nano-particles. Process Biochem., 41: 1193-1197. DOI: 10.1016/ j.Matlet.2006.01.048

Taniai, T., A. Sukuragawa and T. Okutani, 2001. Fluorometric determination of ethanol in liquor samples by flow-injection analysis using an immobilized enzyme-reactor column with packing prepared by coupling alcohol oxidase and peroxidase onto chitosan beads. J. AOAC Int., 84: 1475-1483. PMID: 11601467

Temino, D.M.R.D., W. Hartmeier and M.B. AnsorgeSchumacher, 2005. Entrapment of the alcohol dehydrogenase from Lactobacillus kefir in polyvinyl alcohol for the synthesis of chiral hydrophobic alcohols in organic solvents. Enzyme Microbial. Technol., 36 : 3-9. DOI: 10.1016/j.enzmictec.2004.01.013

Tripathi, P., A. Kumari, P. Rath and A. M. Kayastha, 2007. Immobilization of $\alpha$-amylase from mung beans (Vigna ntarct) on Amberlite MB 150 and chitosan beads. J. Mol. Catalysis B: Enzymatic, 49: 69-74. DOI: 10.1016/j.molcatb.2007.08.011

Vaillant, F., A. Millan, P. Millan, M. Dormier and M. Decloux and M. Reynes, 2000. Co-immobilized pectinlyase and endocellulase on chitin and nylon supports. Process Biochem., 35: 989-96. DOI: 10.1016/S0032-9592(00)00131-X

Vazquez-Duhalt, R., R. Tinoco, P. D'Antonio, L.D.T. Topoleski and G.F. Payne, 2001. Enzyme conjugation to the polysaccharide chitosan: Smart biocatalysts and biocatalytic hydrogels. Bioconjugate Chem., 12: 301-306. PMID: 11312692

Wang, J. G. Zhao, Y. Li, X. Liu and P. Hou, 2012. Reversible immobilization of glucoamylase onto magnetic chitosan nanocarriers. Applied Microbiol. Biotechnol., DOI: 10.1007/s00253-012-3979-2

Wang, Y., J. Zhu, R. Zhu, Z. Zhu and Z. Lai et al., 2003. Chitosan/Prussian blue-based biosensors. Measurement Sci. Technol., 14: 831-836. DOI: 10.1088/0957-0233/14/6/317

Wang, Z.G., L.S. Wan, Z.M. Liu, X.J. Huang and Z.K. $\mathrm{Xu}, 2009$. Enzyme immobilization on electrospun polymer nanofibers: An overview. J. Mol. Catalysis B: Enzymatic, 56: 189-195. DOI: 10.1016/j.molcatb.2008.05.005

Wei, X., J. Cruz and W. Gorski, 2002. Integration of enzymes and electrodes: Spectroscopic and electrochemical studies of chitosan-enzyme films. Analytical Chem., 74: 5039-5046. DOI: $10.1021 / \mathrm{ac} 020216 \mathrm{e}$
Wei, X., M. Zhang and W. Gorski, 2003. Coupling the lactate oxidase to electrodes by ionotropic gelation of biopolymer. Analytical Chem., 75: 2060-2064. PMID: 12720341

$\mathrm{Wu}$, Y., Y. Wang, G. Luo and Y. Dai, 2009. In situ preparation of magnetic $\mathrm{Fe}_{3} \mathrm{O}_{4}$-chitosan nanoparticles for lipase immobilization by crosslinking and oxidation in aqueous solution. Bioresource Technol., 100: 3459-3464. DOI: 10.1016/j.biortech.2009.02.018

Xie, W. and J. Wang, 2012. Immobilized lipase on magnetic chitosan microspheres for transesterification of soybean oil. Biomass Bioenergy, 36: 373-380. DOI: 10.1016/j.biombioe.2011.11.006

$\mathrm{Xu}, \mathrm{Y}$. and Y. Du, 2003. Effect of molecular structure of chitosan on protein delivery properties of chitosan nanoparticles. Int. J. Pharmaceutics, 250: 215-226. PMID: 12480287

Yadav, Y., R. Devi, P. Bhar, S. Singhla and C.S. Pundir, 2012. Immobilization of creatininase, creatinase and sarcosine oxidase on iron oxide nanoparticles/chitosan-g polyaniline modified $\mathrm{Pt}$ electrode for detection of creatinine. Enzyme Microbial. Technol., 50: 247-254. DOI: 10.1016/j.enzmictec.2012.01.008

Yang, K., N.S. Xu and W.W. Su, 2010. Co-immobilized enzymes in magnetic chitosan beads for improved hydrolysis of macromolecular substrates under a time-varying magnetic field. J. Biotechnol., 148: 119-127. DOI: 10.1016/j.jbiotec.2010.05.001

Yao, D., A.G. Vlessidis and N.P. Evmiridis, 2003. Microdialysis sampling and monitoring of uric acid in vivo by a chemiluminescence reaction and an enzyme on immobilized chitosan support membrane. Analytica Chimica Acta, 478: 23-30. DOI: $10.1016 / \mathrm{S} 0003-2670(02) 01484-8$

Yi, S.S., C.W. Lee, J. Kim, D. Kyung and B.G. Kim et al., 2007. Covalent immobilization of wtransaminase from Vibrio fluvialis JS17 on chitosan beads. Process Biochem., 42: 895-898. DOI: 10.1016/j.procbio. 2007.01.008

Zhang, L., X. Zhua, S. Zhenga and H. Sunb, 2009. Photochemical preparation of magnetic chitosan beads for immobilization of pullulanase. Biochem. Eng. J., 46: 83-87. DOI: 10.1016/j.bej.2009.04.024 